Centre interuniversitaire de recherche

en économie quantitative

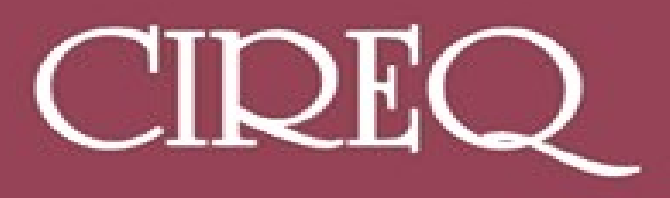

Cahier 16-2013

On the Effects of Mergers on Equilibrium Outcomes in a Common Property Renewable Asset Oligopoly

Hassan BENCHEKROUN and Gérard GAUDET 


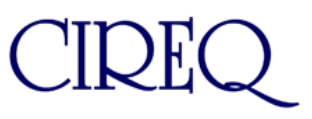

Le Centre interuniversitaire de recherche en économie quantitative (CIREQ) regroupe des chercheurs dans les domaines de l'économétrie, la théorie microéconomique, la macroéconomie et les marchés financiers, la microéconomie appliquée ainsi que l'économie de l'environnement et des ressources naturelles. Ils proviennent principalement des universités de Montréal, McGill et Concordia. Le CIREQ offre un milieu dynamique de recherche en économie quantitative grâce au grand nombre d'activités qu'il organise (séminaires, ateliers, colloques) et de collaborateurs qu'il reçoit chaque année.

The Center for Interuniversity Research in Quantitative Economics (CIREQ) regroups researchers in the fields of econometrics, microeconomic theory, macroeconomics and financial markets, applied microeconomics, and environmental and natural resources economics. They come mainly from the Université de Montréal, McGill University and Concordia University. CIREQ offers a dynamic environment of research in quantitative economics thanks to the large number of activities that it organizes (seminars, workshops, conferences) and to the visitors it receives every year.

\title{
Cahier 16-2013
}

\section{On the Effects of Mergers on Equilibrium Outcomes in a Common Property Renewable Asset Oligopoly}

\author{
Hassan BENCHEKROUN and Gérard GAUDET
}


Ce cahier a également été publié par le Département de sciences économiques de l'Université de Montréal sous le numéro (2013-11).

This working paper was also published by the Department of Economics of the University of Montreal under number (2013-11).

Dépôt légal - Bibliothèque nationale du Canada, 2013, ISSN 0821-4441

Dépôt légal - Bibliothèque et Archives nationales du Québec, 2013

ISBN-13 : 978-2-89382-657-8 



\title{
On the effects of mergers on equilibrium outcomes in a common property renewable asset oligopoly ${ }^{1}$
}

\author{
Hassan Benchekroun \\ Department of Economics and CIREQ \\ McGill University \\ and \\ Gérard Gaudet \\ Département de sciences économiques and CIREQ \\ Université de Montréal
}

October 3, 2013

\footnotetext{
${ }^{1}$ This research has benefited from the financial support of the Fonds québécois de la recherche sur la société et la culture (FQRSC) and the Social Sciences and Humanities Research Council of Canada (SSHRC). Please address all correspondance to Hassan Benchekroun, Department of Economics, McGill University, 855 Sherbrooke Street West, Montreal, QC H3A-2T7, Canada. Email: hassan.benchekroun@mcgill.ca
} 


\begin{abstract}
This paper examines a dynamic game of exploitation of a common pool of some renewable asset by agents that sell the result of their exploitation on an oligopolistic market. A Markov Perfect Nash Equilibrium of the game is used to analyze the effects of a merger of a subset of the agents. We study the impact of the merger on the equilibrium production strategies, on the steady states, and on the profitability of the merger for its members. We show that there exists an interval of the asset's stock such that any merger is profitable if the stock at the time the merger is formed falls within that interval. That includes mergers that are known to be unprofitable in the corresponding static equilibrium framework.
\end{abstract}

JEL Classification: C73, D43, L13, Q20

Keywords: Mergers, Dynamic games, Oligopoly, Common property, Renewable resources. 


\section{Introduction}

It is well known since Salant, Switzer and Reynolds (1983) that a merger of a subset of the players acting to maximize the joint profits of the subset in a static quantity-setting oligopoly is not necessarily profitable. In fact they show that in the case of linear demand and constant marginal cost no less than $80 \%$ of the players must be part of the merger if it is to be profitable. In particular, a merger of two players is never profitable unless it results in a monopoly. Subsequent generalizations have confirmed that the merger must always involve a significant share of the market in order to be profitable for its members. ${ }^{1}$ The reason is that, in a situation of strategic substitutes, the firms outside the merger react to the joint reduction of output by the members of the merger by increasing their own output. The resulting aggregate effect on industry output will be positive, and hence the effect on price negative, unless the proportion of insiders is large enough for their reduction of output to compensate the increase of output by the outsiders.

The purpose of this paper is to reexamine the effect on the equilibrium strategies and on profit of a similar merger in the context of a dynamic common property resource oligopoly. In the pre-merger equilibrium a fixed number of firms are assumed to exploit a renewable resource stock under common property and sell their product on an oligopolistic output market. In such a dynamic context each firm benefits from two sources of rent: the rent due to its oligopolistic market power on the output market, as in the purely static framework of Salant et al. (1983), and the rent due to its access to the common resource stock. That stock is an asset which, if left unexploited, reproduces itself naturally at a rate which depends on the size of the stock. The marginal value attached to this asset by the firm varies inversely with the level of the stock and is taken into account when deciding on its rate of exploitation. In such a context, the profitability of a merger will depend on the level of the common stock at the time the merger is formed. It turns out that in the presence of the resource dynamics there always exists an initial interval of the stock inside of which any merger is profitable,

\footnotetext{
${ }^{1}$ Such a generalization is provided, among others, by Gaudet and Salant (1991), who analyze in a very general framework the profitability of an exogenous reduction of production by a subset of the firms in an oligopoly, mergers being a particular case of this.
} 
even a merger of two firms.

The analysis is carried out in continuous time, using a non-cooperative differential game framework (see Dockner, Jorgensen, Long and Sorger (2000)). We focus on closed-loop strategies, whereby the strategy of a firm is a production rule that depends on the current stock of the asset (i.e. markovian strategies). ${ }^{2}$ The equilibrium of the game is very closely related to that proposed in Benchekroun $(2003,2008)$. Contrary to many other analyses of the exploitation of a common pool of a renewable asset, in which each agent's net benefit function depends only on the consumption of its own production, there being no interaction in the output market (see for instance Levhari and Mirman (1980), Plourde and Yeung (1989), Benhabib and Radner (1992), Dutta and Sundaram (1993a,b) and Dockner and Sorger (1996)), in our model, as in Benchekroun (2003, 2008), the agents interact in the output market as well as in the exploitation of the common resource pool. ${ }^{3}$ This is of course essential in order to analyze the effect of a merger in a dynamic context that corresponds to the static-Cournot context of Salant et al. (1983). As in Salant et al. (1983) we do not model nor address the issue of the decision to enter a merger, but simply assume the merger to be exogenously determined. Contrary to the static framework, in a dynamic setting one could raise the issues of the timing of the merger, as well as of the possibility of the merger being disbanded after some time and maybe even reformed later. We will neglect those issues here and assume that the merger is formed at the outset and is irreversible, so as to better concentrate on illustrating the contrasts with the static game and the role played by the renewability of the resource.

The rationale behind the result that any merger is profitable within some interval of the stock rests on the fact that, in this dynamic game, an action by one of the players that changes the level of the stock has an effect on the decision of all its rivals. Indeed, since each

\footnotetext{
${ }^{2}$ Open-loop strategies, whereby the firms commit at the outset to a production path that depends only on time, are inappropriate for studying a game of exploitation of an asset under common property (see Eswaran and Lewis (1984) or Clemhout and Wan (1991).

${ }^{3}$ Some notable exceptions that take into account competition in the output market are Karp (1992a,b), Mason and Polasky (1997) and, more recently, Fujiwara (2011) and Colombo and Labrecciosa (2013). Howerver, they all put the emphasis on very different issues then the one that concerns us here. Colombo and Labrecciosa (2013) also make use of the same specification of the dynamics of the resource as in Benchekroun (2003, 2008).
} 
firm conditions its production decision on the size of the stock, when a firm (or a group of firms) changes its production the other firms' production decisions will now change for two reasons: the resulting change in the market price, as in the static context, and the resulting change in the stock of the resource, which is absent in the static equilibrium. As we will show, because of the presence of this stock effect on the rivals' production there is always an interval of stock such that overall equilibrium production falls following a merger of a subset

of the firms. This explains why there is always some interval of the stock within which any merger is profitable, even one that is unprofitable in the static-Cournot equilibrium.

We will use the expression "merger" throughout, but the same analysis applies directly to a cartel or a coalition of a subset of the agents with the goal of maximizing their joint profits; the reader may prefer to think instead in those terms.

In Section 2 we present the model and characterize a pre-merger Markov Perfect Nash Equilibrium (MPNE). The three subsections of Section 3 analyze the effects of a merger on the equilibrium strategies, the steady-states and the profits of its members, in that order. A brief conclusion follows in Section 4.

\section{The Model}

Let $S$ denote the stock of some renewable asset, the access to which is shared by $K$ firms. The firms exploit the asset to produce an output that they sell in an oligopolistic market. It will be assumed for simplicity that one unit of the asset is transformed into one unit of the output, at zero cost. Denote by $q_{i}(t)$ firm $i$ 's resulting output at time $t$. The inverse demand function for this output is given by

$$
P(Q)=a-b Q
$$

where $Q=\sum_{i=1}^{K} q_{i}$.

In the absence of exploitation, the stock of the asset (a fish population, for instance) 
evolves as a function of the current stock according to the following dynamics:

$$
\dot{S}=F(S), S(0)=S_{0}
$$

where, as in Benchekroun (2003, 2008),

$$
F(S)=\left\{\begin{array}{lll}
\delta S & \text { for } \quad S \leq S_{y} \\
\delta S_{y}\left(\frac{\bar{S}-S}{\bar{S}-S_{y}}\right) & \text { for } & S>S_{y}
\end{array}\right.
$$

The positive parameter $\delta$ is the intrinsic growth rate: when the stock of the asset is very small, there is no habitat constraint and it grows at an exponential rate (see for example Clark (1990)). The maximum sustainable yield of the asset is $\delta S_{y}$; beyond $S_{y}$ the asset grows at a decreasing rate. The parameter $\bar{S}$ represents the carrying capacity of the habitat, beyond which the asset's growth rate becomes negative. For simplicity, we normalize $\bar{S}$ to 1 in what follows.

We assume that the intrinsic growth rate satisfies Assumption $1 \quad \delta>\delta_{0} \equiv \operatorname{Max}\left\{\frac{r\left(1+K^{2}\right)}{2}, \frac{a\left(1+K^{2}\right)}{S_{y} b(1+K)^{2}}\right\}$,

where $r$ denotes the positive rate of discount, the same for all firms. This assumption implies that $\delta / r$ is strictly bounded from below, which ensures the existence of a strictly interior stable steady-state stock. $^{4}$

We restrict attention to equilibria in stationary Markov strategies. Stationary Markov strategies in this context are decision rules whereby a firm conditions its rate of exploitation of the resource on the current resource stock: $q_{i}(t)=\phi_{i}(S(t))$. Firm $i, i=1, \ldots, K$, takes the strategies of its $(K-1)$ rivals as given in choosing its own decision rule, $q_{i}=\phi_{i}(S)$, in order to maximize the present value of its flow of instantaneous profits,

$$
J_{i}=\int_{0}^{\infty} e^{-r t} P\left(q_{i}+\sum_{j \neq i} \phi_{j}(S)\right) q_{i} d t
$$

\footnotetext{
${ }^{4}$ The imposition of such a lower bound is common in the literature. See for instance Benchekroun (2008), Dockner and Sorger (1996) or Dutta and Sundaram (1993a,b).
} 
subject to

$$
\dot{S}=F(S)-q_{i}-\sum_{j \neq i} \phi_{j}(S), \quad S(0)=S_{0}
$$

and

$$
q_{i} \geq 0, \quad \lim _{t \rightarrow \infty} S(t) \geq 0
$$

The following proposition characterizes a MPNE to this non-cooperative differential game.

Proposition 1 Let $\phi^{*}$ denote the following production strategy:

$$
\phi^{*}(S, K)=\left\{\begin{array}{lll}
0 & \text { for } & 0 \leq S \leq S_{1, K} \\
\frac{a-D-E S}{(1+K) b} & \text { for } & S_{1, K}<S \leq S_{2, K} \\
q_{K}^{c} & \text { for } & S_{2, K}<S
\end{array}\right.
$$

where

$$
\begin{gathered}
D=(2 \delta-r) \frac{a\left(1+K^{2}\right)}{2 K^{2} \delta}, \quad E=-(2 \delta-r) \frac{b(1+K)^{2}}{2 K^{2}}, \quad q_{K}^{c}=\frac{a}{(1+K) b} \\
S_{1, K}=\frac{a-D}{E}=\frac{a\left(2 \delta-r\left(1+K^{2}\right)\right)}{\delta b(2 \delta-r)(1+K)^{2}}, \quad S_{2, K}=-\frac{D}{E}=\frac{a\left(1+K^{2}\right)}{\delta b(1+K)^{2}}
\end{gathered}
$$

The vector of closed-loop strategies $\left(\phi^{*}, . ., \phi^{*}\right)$ constitutes a symmetric MPNE.

Proof. See Benchekroun (2008).

Note that since $\delta>\frac{a\left(1+K^{2}\right)}{S_{y} b(1+K)^{2}}$ by Assumption 1, we have $S_{2, K}<S_{y}$. It also follows from Assumption 1 that $2 \delta-r>0$ and therefore

$$
\frac{d S_{1, K}}{d K}=-\frac{2 a(2 \delta-r+K r)}{(2 \delta-r)(1+K)^{3}}<0
$$

Furthermore

$$
\frac{d S_{2, K}}{d K}=\frac{2 a(K-1)}{\delta b(1+K)^{3}}>0 .
$$

Hence the interval $\left[S_{1, K}, S_{2, K}\right]$ increases with $K$. 
Note also that $q_{K}^{c}$ corresponds to the symmetric Cournot equilibrium output of each firm in a static oligopoly with a demand function $P=a-b Q$ and zero cost of production. Therefore, in this equilibrium, if the asset is "abundant" $\left(S \geq S_{2, K}\right)$ firms simply adopt the production strategy they would in the corresponding static Cournot game.

Another interesting feature of this equilibrium is that, although all $K$ firms have free access to the asset and form an oligopoly in the output market, each firm decides voluntarily to abstain from exploitation if the asset's stock is too small $\left(S<S_{1, N}\right)$. Hence the asset is never depleted. Benhabib and Radner (1992) also exhibit equilibria where both agents (they consider a duopoly) voluntarily cease consumption if the asset's stock is below a given threshold. In the context where a given finite number of firms have access to the common pool of the renewable asset and compete in an oligopolistic output market, rents will accrue to each firm both from having access to the asset and from the market power it holds in the output market. ${ }^{5}$

Let $V(S, K)$ denote the value function of a firm in this symmetric equilibrium of $K$ firms when the stock is $S$; it is equal to the sum of its net benefits along the equilibrium path discounted to infinity at the rate $r$. As is shown in Benchekroun (2008, Proposition 1 and Appendix A), it is given by

$$
V(S, K)=\left\{\begin{array}{lll}
W\left(S_{1, K}, K\right)\left(\frac{S}{S_{1, K}}\right)^{\frac{r}{\delta}} & \text { if } \quad 0 \leq S<S_{1, K} \\
W(S, K) & \text { if } \quad S_{1, K} \leq S<S_{2, K} \\
\frac{a^{2}}{r b(1+K)^{2}} & \text { if } \quad S_{2, K} \leq S
\end{array}\right.
$$

where

$$
W(S, K)=\frac{1}{2} E S^{2}+D S+G .
$$

\footnotetext{
${ }^{5}$ This is unlike the equilibria constructed in Levhari and Mirman (1980) and Dockner and Sorger (1996), where the exploitation of the asset is positive for any positive level of the stock. In Levhari and Mirman (1980) each agent's instantaneous utility is a logarithmic function of its consumption and in Dockner and Sorger (1996) each agent's instantaneous utility is the square root of its consumption. Therefore, in both cases, the marginal utility of consumption tends to infinity when consumption tends to zero. Also, in both of those cases, the agents do not compete in an output market, but simply consume their own output.
} 
The function $V(S, K)$ is everywhere twice continuously differentiable with respect to $S$.

Note that for $S \geq S_{2, K}$, the value function is simply equal to the profit accruing to the firm in the static Cournot equilibrium, discounted to infinity. This is independent of the stock. For those values of $S$, the value of the firm is simply the discounted rent accruing to it from its market power, which depends on $K$ but not on $S$. On the other hand, for $S<S_{2, K}$ the value function accounts for both the market rent and the asset rent. The latter depends on the size of the asset.

The value to a firm of an additional unit of common stock, which corresponds to the marginal asset rent, is

$$
\frac{\partial V(S, K)}{\partial S}= \begin{cases}W\left(S_{1, K}, K\right) \frac{r}{\delta S_{1, K}}\left(\frac{S}{S_{1, K}}\right)^{\frac{r}{\delta}-1} & \text { if } \quad 0 \leq S<S_{1, K} \\ \frac{\partial W(S, K)}{\partial S} & \text { if } \quad S_{1, K} \leq S<S_{2, K} \\ 0 & \text { if } \quad S_{2, K} \leq S .\end{cases}
$$

As can be seen from the above, for $S<S_{2, K}$ the rent associated with an additional unit of the asset is decreasing with its stock, and it tends to $+\infty$ as the stock approaches zero. This explains why, in this equilibrium, firms prefer to leave the asset grow and refrain from any exploitation when $S<S_{1, K}$. It is only when the value of the marginal unit of the asset has decreased sufficiently as the stock increases that they begin exploitation.

As a corollary to Proposition 1, we can state the following:

\section{Corollary 1}

a. The strategy $\phi^{*}(S . K)$ is a non-decreasing function of the asset's stock, and since the equilibrium is symmetric, so is the industry's total exploitation, $\Phi(S, K)=K \phi^{*}(S . K)$.

b. When $\delta S_{y}<\frac{a K}{b(1+K)}=Q_{K}^{c}\left(=K \phi^{*}\left(S_{2, K}\right)\right)$, so that the static Cournot output exceeds the maximum sustainable yield, there exists a unique positive stationary stock $S_{1, K}^{\infty} \in$ $\left(S_{1, K}, S_{2, K}\right)$ given by

$$
S_{1, K}^{\infty}=\frac{a}{b \delta(1+K)} \frac{2 \delta-r\left(1+K^{2}\right)}{2 \delta-r(1+K)} .
$$


The closed-loop subgame perfect equilibrium path of the asset's stock converges to $S_{1, K}^{\infty}$ (see Figure 1).

c. When $\delta S_{y}>\frac{a K}{b(1+K)}=Q_{K}^{c}\left(=K \phi^{*}\left(S_{2, K}\right)\right)$, so that the maximum sustainable yield exceeds the static Cournot output, there exist three positive stationary stocks, $S_{1, K}^{\infty}$, $S_{2, K}^{\infty}$ and $S_{3, K}^{\infty}$ (see Figure 2) with

$$
S_{1, K}^{\infty}<S_{2, K}^{\infty}=\frac{a K}{\delta b(1+K)}<S_{3, K}^{\infty}=1-\frac{\left(1-S_{y}\right) a K}{\delta S_{y} b(1+K)}
$$

$S_{1, K}^{\infty}$ and $S_{3, K}^{\infty}$ being stable, while $S_{2, K}^{\infty}$ is not, the steady-state value of the stock depends on the initial stock: when $S_{0}<S_{2, K}^{\infty}$ the stock converges to $S_{1, K}^{\infty}$, and when $S_{0}>S_{2, K}^{\infty}$ the stock converges to $S_{3, K}^{\infty}$.

Proof. See Benchekroun (2008, Appendix C).

It follows from Part c. of Corollary 1 that if, ceteris paribus, the intrinsic growth rate is sufficiently high $\left(\delta>\frac{a K}{S_{y} b(1+K)}\right)$ and the stock is initially large enough $\left(S_{0}>S_{2, K}\right)$ and remains so, exploiting the asset at a rate corresponding to the equilibrium $\left(q_{K}^{c}, . ., q_{K}^{c}\right)$ of a purely static Cournot game is sustainable as a closed-loop Nash equilibrium. The firms can play forever the equilibrium of this static Cournot game.

We now turn to the analysis of the effects of a merger of a subset of the firms, whose objective is the maximization of the joint profits of the members.

\section{The equilibrium effects of a merger}

Consider a pre-merger situation where $N$ firms (i.e. $K=N$ ) compete in the exploitation of the resource and in the output market. We then have an $N$-firms non-cooperative equilibrium of the dynamic game. A subset of $M<N$ firms is assumed to form a merger, with the objective of maximizing the joint profits of the $M$ members of the merger in the ensuing dynamic game. Since the marginal cost of each firm is constant and identical (assumed to be zero for simplicity), the post-merger equilibrium will correspond to a non-cooperative equilibrium of the game played by $N-M+1$ firms (i.e. $K=N-M+1$ ). 


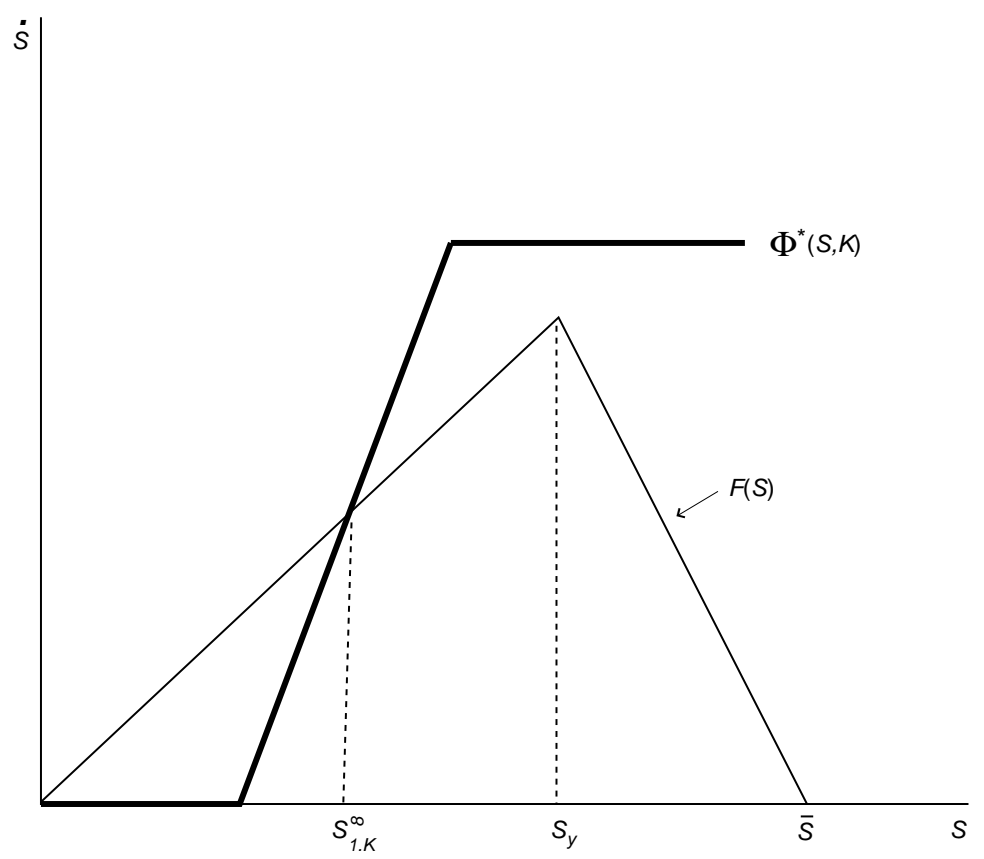

Figure 1: A unique positive steady state

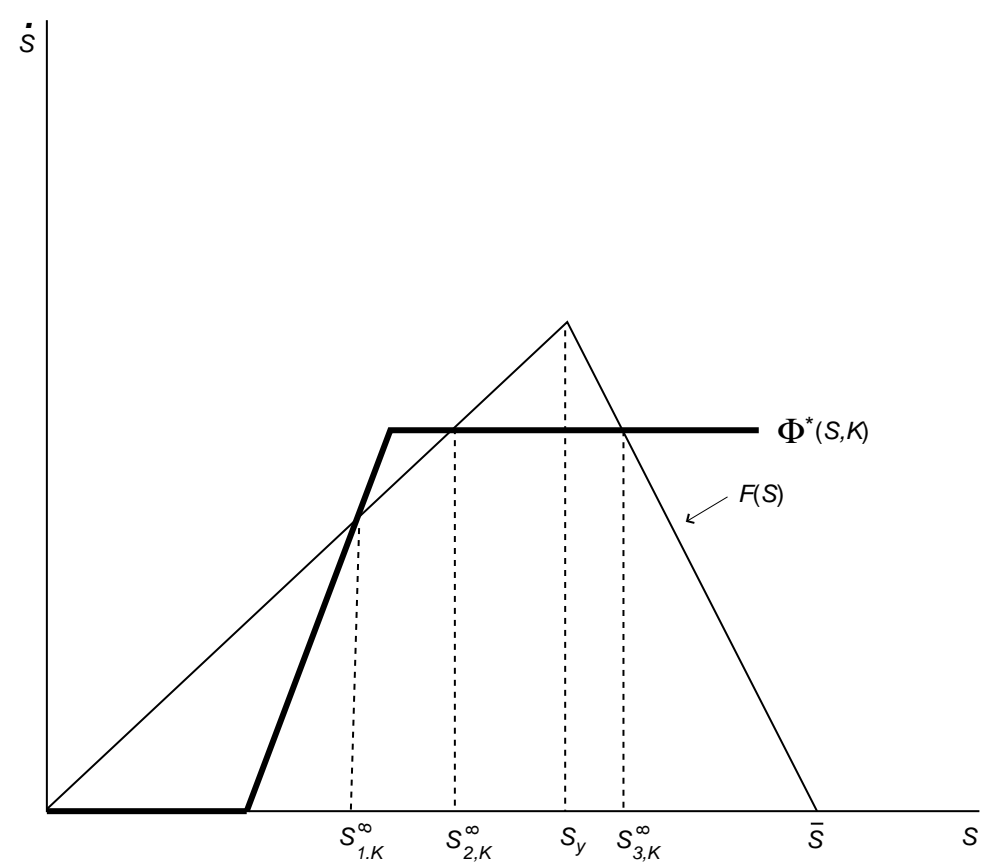

Figure 2: Three positive steady states 
To compare the post-merger and pre-merger equilibria therefore amounts simply to comparing the equilibrium described in the previous section for $K=N-M+1$ with that for $K=N$, as in Salant et al. (1983). In the static framework analyzed by Salant et al. (1983), such a merger is profitable only if $M / N$ is sufficiently large. In fact, Salant et al. (1983) show that with a linear demand and constant marginal cost, as we are assuming, the merger must involve at least $80 \%$ of the firms in order to be profitable. We will show in what follows that in the dynamic context considered here even mergers as small as $M=2$ will be profitable in some instances.

Contrary to the static framework of Salant et al. (1983), in our dynamic framework the timing of the merger can become an issue, and a merger might be profitable for only a finite period of time, after which it would be dissolved. We will assume in what follows that the merger occurs only at time $t=0$ with stock $S_{0}>0$ and is irreversible. It is sufficient to limit our attention to such a situation since our purpose is to illustrate circumstances under which some mergers can be profitable in the dynamic framework but would not be in the static framework. The focus will therefore be strictly on the role played by the resource dynamics on the effects of the merger.

We now analyze, in order, the effects of the merger on the equilibrium strategies and steady-states, and those on the firms' profits.

\subsection{The effects on the equilibrium strategies}

The following proposition compares the pre-merger and post-merger individual equilibrium production strategies of the firms.

Proposition 2 For any $N>2$ and any $M<N$ there exists a $\tilde{S} \in\left(S_{1, N-M+1}, S_{2, N-M+1}\right)$ such that

$$
\phi_{N-M+1}^{*}-\phi_{N}^{*}\left\{\begin{array}{lll}
<0 & \text { for } & S_{1, N}<S<\tilde{S} \\
>0 & \text { for } & \tilde{S}<S
\end{array}\right.
$$

while

$$
\phi_{N-M+1}^{*}=\phi_{N}^{*}=0 \quad \text { for } \quad S<S_{1, N}
$$


Proof. We know from (7) and (8) that

$$
S_{1, N}<S_{1, N-M+1} \quad \text { and } \quad S_{2, N-M+1}<S_{2, N}
$$

The statement (12) follows from the definition of $S_{1, K}$ and the fact that $S_{1, N}<S_{1, N-M+1}$. We also know from Proposition 1 that $\phi_{N}^{*}=a /[b(N+1)]$ for $S \geq S_{2, N}$ and $\phi_{N}^{*}<a /[b(N+1)]$ for $S<S_{2, N}$. Since $S_{2, N-M+1}<S_{2, N}$, it follows that

$$
\phi_{N-M+1}^{*}(S)=\frac{a}{b(N-M+2)}>\frac{a}{b(N+1)} \geq \phi_{N}^{*}(S) \quad \text { for all } \quad S>S_{2, N-M+1} .
$$

For $S \in\left[S_{1, N-M+1}, S_{2, N-M+1}\right]$ we have that $\phi_{N-M+1}^{*}(S)-\phi_{N}^{*}(S)$ is linear in $S$, takes a negative value at $S_{1, N-M+1}$ and a positive value at $S_{2, N-M+1}$. It follows that the production strategies $\phi_{N-M+1}^{*}(S)$ and $\phi_{N}^{*}(S)$ must intersect at some $\tilde{S} \in\left(S_{1, N-M+1}, S_{2, N-M+1}\right)$ and (11) holds.

Hence, the effect of the merger on the equilibrium level of production of each individual firm will depend on the stock at the time the merger is formed. As long as the initial stock is such that production was positive to begin with (i.e. $S \geq S_{1, N}$ ), the production of individual firms will, after the merger, be smaller for low stocks $(S<\tilde{S})$ and larger for high stocks $(S>\tilde{S})$. This is illustrated in Figure 3 .

Now let $\Phi^{*}(S)=\sum \phi_{i}^{*}(S)$, the total equilibrium production of the industry. The following proposition compares this total equilibrium production before and after the merger.

Proposition 3 For any $N>2$ and any $M<N$ there exist a $\hat{S}_{1} \in\left(S_{1, N-M+1}, S_{2, N-M+1}\right)$ and a $\hat{S}_{2} \in\left(S_{2, N-M+1}, S_{2, N}\right)$ such that

$$
\Phi_{N-M+1}^{*}(S)>\Phi_{N}^{*}(S) \text { if and only if } \hat{S}_{1}<S<\hat{S}_{2}
$$

Proof. See Appendix A.

Hence, for any partial merger, there exists a range of initial stocks such that total production increases as a result of the merger. Outside that range, total production will be strictly 


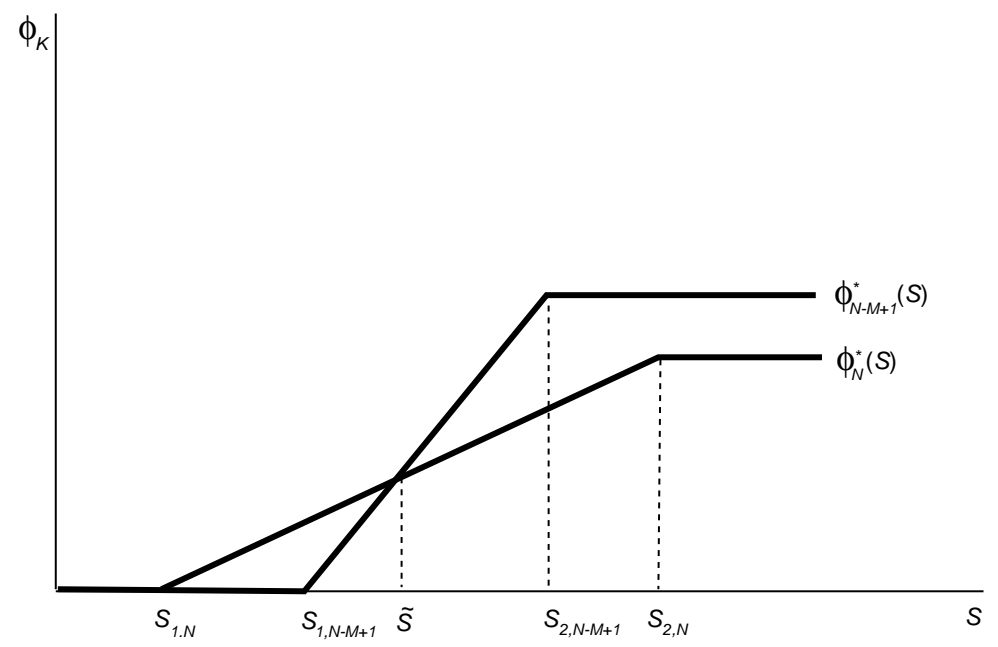

Figure 3: Individual equilibrium production strategies

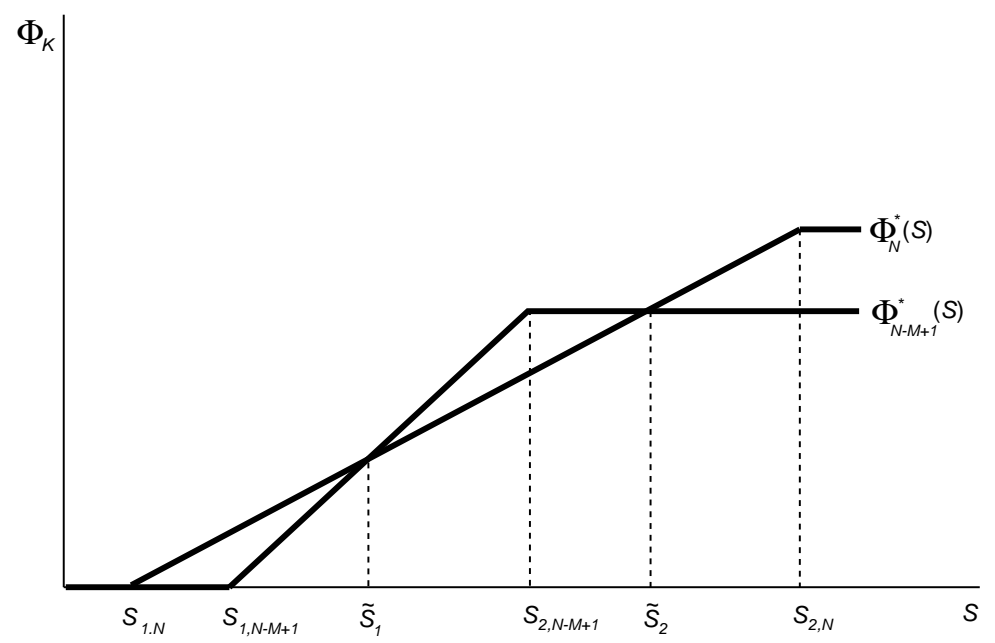

Figure 4: Aggregate equilibrium production strategies

lower after the merger except for $S \leq S_{1, N}$, where it remains at zero. This is illustrated in Figure 4 .

\subsection{The effects on the equilibrium steady states}

To analyze the effect of the merger on the equilibrium steady states it is useful to distinguish the two cases that may characterize the pre-merger equilibrium, as noted in Corollary 1 . In the case where $\delta S_{y}<\frac{a N}{b(1+N)}$, there exists a single strictly positive steady-state equilibrium 
prior to the merger, as illustrated in Figure 1. In the case where $\delta S_{y}>\frac{a N}{b(1+N)}$, there exists three strictly positive steady states prior to the merger, as illustrated in Figure 2.

When $\delta S_{y}<\frac{a N}{b(1+N)}$, two possibilities arise if a merger of size $M<N$ is formed. If $M$ is such that $\delta S_{y}<\frac{a(N-M+1)}{b(N-M+2)}$, then there will still be a unique stationary equilibrium after the merger. But if $\delta S_{y}>\frac{a(N-M+1)}{b(N-M+2)}$, then we will go from one to three steady states when the merger is formed.

In the $K$-firms equilibrium, we know (see Corollary 1) that if $\delta S_{y}<\frac{a K}{b(1+K)}$ there is a unique and stable positive steady-state stock. It can be written (see Corollary 1.b)

$$
S_{1, K}^{\infty}=\frac{a}{\delta b} f(K)
$$

where

$$
f(K)=\frac{d-K^{2}}{(1+K)(d-K)} \quad \text { and } \quad d=\frac{2 \delta}{r}-1
$$

Note that $d$ is strictly positive, since $\frac{2 \delta}{r}>1+K^{2}$ by Assumption 1 . No matter what its initial level, the stock converges to $S_{1, K}^{\infty}$ in the long-run.

On the other hand, if $\delta S_{y}>\frac{a K}{b(1+K)}$, there are two more steady states, in addition to $S_{1, K}^{\infty}$, namely $S_{2, K}^{\infty}$ and $S_{3, K}^{\infty}$, whose expressions are given in Corollary 1.c. The steady state $S_{2, K}^{\infty}$ being unstable, the stock converges in the long run to $S_{1, K}^{\infty}$ if $S_{0}<S_{2, K}^{\infty}$ and to $S_{3, K}^{\infty}$ if $S_{0}>S_{2, K}^{\infty}$

In all instances, there will be a stable stationary state such as $S_{1, K}^{\infty}$ both before and after the merger, which will be given by $S_{1, N}^{\infty}=\frac{a}{\delta b} f(N)$ and $S_{1, N-M+1}^{\infty}=\frac{a}{\delta b} f(N-M+1)$ respectively. Since $f^{\prime}(K)<0$ (by Assumption 1), we will have

$$
S_{1, N-M+1}^{\infty}-S_{1, N}^{\infty}=\frac{a}{\delta b}[f(N-M+1)-f(N)]>0 .
$$

Therefore the merger results in an increase of the stationary stock in this case.

It follows that if $\delta S_{y}<\frac{a N}{b(1+N)}$ and $\delta S_{y}<\frac{a(N-M+1)}{b(N-M+2)}$, the stock will be converging in the long run to $S_{1, N}^{\infty}$ before the merger and to $S_{1, N-M+1}^{\infty}$ after the merger, no matter what 
the stock when the merger is formed. The steady-state level of aggregate production will increase from $\delta S_{1, N}^{\infty}$ to $\delta S_{1, N-M+1}^{\infty}$. On the other hand, if $\delta S_{y}<\frac{a N}{b(1+N)}$ and $\delta S_{y}>\frac{a(N-M+1)}{b(N-M+2)}$, then the stock always converges to $S_{1, N}^{\infty}$ before the merger, but after the merger it will converge to $S_{1, N-M+1}^{\infty}$ if $S_{0}<S_{2, N-M+1}^{\infty}$ and to $S_{3, N-M+1}^{\infty}$ if $S_{0}>S_{2, N-M+1}^{\infty}$. In the latter case, this means that the aggregate steady-state level of production increases from $\delta S_{1, N}^{\infty}$ to $\delta S_{y}\left(1-S_{3, N-M+1}^{\infty}\right) /\left(1-S_{y}\right)$.

In the case where $\delta S_{y}>\frac{a N}{b(1+N)}$, the three steady states will exist both before and after the merger. It is straightforward to verify, using their expressions in Corollary 1.c, that,

$$
S_{2, N-M+1}^{\infty}-S_{2, N}^{\infty}<0
$$

and

$$
S_{3, N-M+1}^{\infty}-S_{3, N}^{\infty}>0
$$

The stationary stock will decrease as a result of the merger in the case of $S_{2, K}^{\infty}$ and will increase in the case of $S_{3, K}^{\infty}$.

It follows that if $S_{0}>S_{2, N}^{\infty}$ the merger will result in the stock converging to $S_{3, N-M+1}^{\infty}$ instead of $S_{3, N}^{\infty}$, with a steady-state level of aggregate production $\delta S_{y}\left(1-S_{3, N-M+1}^{\infty}\right) /(1-$ $\left.S_{y}\right)<\delta S_{y}\left(1-S_{3, N}^{\infty}\right) /\left(1-S_{y}\right)$. If $S_{0}<S_{2, N-M+1}^{\infty}$, then the long-run stationary stocks will be

$S_{1, N-M+1}^{\infty}>S_{1, N}^{\infty}$. Finally, if $S_{2, N-M+1}^{\infty}<S_{0}<S_{2, N}^{\infty}$, then the steady-state stock converges to $S_{3, N-M+1}^{\infty}$ instead of $S_{1, N}^{\infty}$, with an aggregate level of production $\delta S_{y}\left(1-S_{3, N-M+1}^{\infty}\right) /\left(1-S_{y}\right)>$ $\delta S_{1, N}^{\infty}$.

\subsection{The effects on the profits of the merged firms}

Because the equilibrium under a merger of $M$ firms corresponds to the equilibrium of a non-cooperative game between $N-M+1$ firms, using (9) we know that the equilibrium value of the merger is given by

$$
\Pi(M, N, S) \equiv V(S, N-M+1)
$$


which is worth $\Pi(M, N, S) / M$ to each member of the merger. The merger of $M$ firms is therefore profitable for its members if and only if

$$
\Pi(M, N, S)>M \Pi(1, N, S)
$$

or

$$
I(M, N, S)=\Pi(M, N, S)-M \Pi(1, N, S)>0 .
$$

Clearly the profitability of the merger depends on both $M$ and $N$, as in the purely static framework of Salant et al. (1983), but also now possibly on the stock at the time the merger is formed, which we have assumed to be $t=0$ with stock $S_{0}$. It is useful to distinguish four regions for $S_{0}$, namely Region I: $S_{0} \in\left(S_{2, N}, \infty\right)$, Region II: $S_{0} \in\left[S_{1, N-M+1}, S_{2, N}\right]$, Region III: $S_{0} \in\left[S_{1, N}, S_{1, N-M+1}\right)$ and Region IV: $S_{0} \in\left(0, S_{1, N}\right)$.

The following proposition characterizes how the profitability function $I(M, N, S)$ varies with $S$.

Proposition 4 For any $N>2$ and $M<N$, the profitability function $I(M, N, S)$ is continuously differentiable in $S$ and

1. independent of $S$ in Region I;

2. strictly decreasing in $S$ in Region II;

3. strictly concave and reaches an interior maximum in $S$ in Region III;

4. strictly increasing in $S$ in Region $I V$.

Proof. See Appendix B

Corollary 2 If a merger of $M$ firms is profitable in the static Cournot equilibrium it will also be profitable in the dynamic equilibrium for all $S$.

Proof. Follows immediately from Proposition 4 and the fact that the function $I(M, N, S)$ is continuous in $S$, with $I(M, N, 0)=0$. 
It also follows from Part 4 of the proposition that any merger will be profitable over some range of the resource stock. This means that mergers that are unprofitable in the purely static Cournot framework of Salant et al. (1983) will be profitable in the noncooperative dynamic game for some values of the stock. This is illustrated in the following proposition and its corollary for the case of $M=2$, which is known to be unprofitable in the static framework of Salant et al. (1983). ${ }^{6}$

Proposition 5 There exists a unique $\hat{\delta}$ such that

$$
I\left(2, N, S_{1, N-2+1}\right)\left\{\begin{array}{l}
>0 \text { for all } \delta \in\left[\frac{r}{2}\left(1+N^{2}\right), \hat{\delta}\right) \\
=0 \quad \text { for } \delta=\hat{\delta} \\
<0 \quad \text { for all } \delta>\hat{\delta}
\end{array}\right.
$$

\section{Proof. See Appendix C}

Corollary 3 There exists a unique $\hat{S}$ such that a merger of $M=2$ is profitable for all $S \in(0, \hat{S})$, where

$$
\begin{aligned}
& \hat{S} \in\left(S_{1, N}, S_{1, N-M+1}\right) \text { for } \delta>\hat{\delta} \\
& \hat{S} \in\left(S_{N-M+1}, S_{2, N}\right) \text { for } \delta \in\left[\frac{r}{2}\left(1+N^{2}\right), \hat{\delta}\right) .
\end{aligned}
$$

Proof. Since, from Proposition $4, I(M, N, S)$ is a continuously decreasing function of $S$ for all $S \in\left(\arg \max _{S} I(M, N, S), S_{2, N}\right)$, and since $I(2, N, S)<0$ for all $S \geq S_{2, N}$, there must exist a unique $\hat{S}$ such that $I(2, N, S)>0$ for all $S \in(0, \hat{S})$. Since, from Proposition 5 , $I\left(2, N, S_{1, N-2+1}\right)<0$ for $\delta>\hat{\delta}$ and $I\left(2, N, S_{1, N-2+1}\right)>0$ for $\delta \in\left[\frac{r}{2}\left(1+N^{2}\right), \hat{\delta}\right)$, it must be that $\hat{S} \in\left(S_{1, N}, S_{1, N-M+1}\right)$ for $\delta>\hat{\delta}$ and $\hat{S} \in\left(S_{1, N-M+1}, S_{2, N}\right)$ for $\delta \in\left[\frac{r}{2}\left(1+N^{2}\right), \hat{\delta}\right)$.

Figure 5 illustrates the case of $\hat{S} \in\left(S_{1, N-M+1}, S_{2, N}\right)$.

The difference in the profitability of the merger between the static and the dynamic framework is due to the presence of a scarcity rent on the resource in the latter. As already noted, given the number of firms, it can be seen from (10) that for $S<S_{2, K}$ the rent

\footnotetext{
${ }^{6}$ The proposition can obviously be extended to any merger of $M>2$ that is unprofitable in the static Cournot framework of Salant et al. (1983): $M=2$ is the smallest possible merger and profitability increases with $M$, reaching profitability for $M \geq .8 N$ when demand and cost are linear.
} 


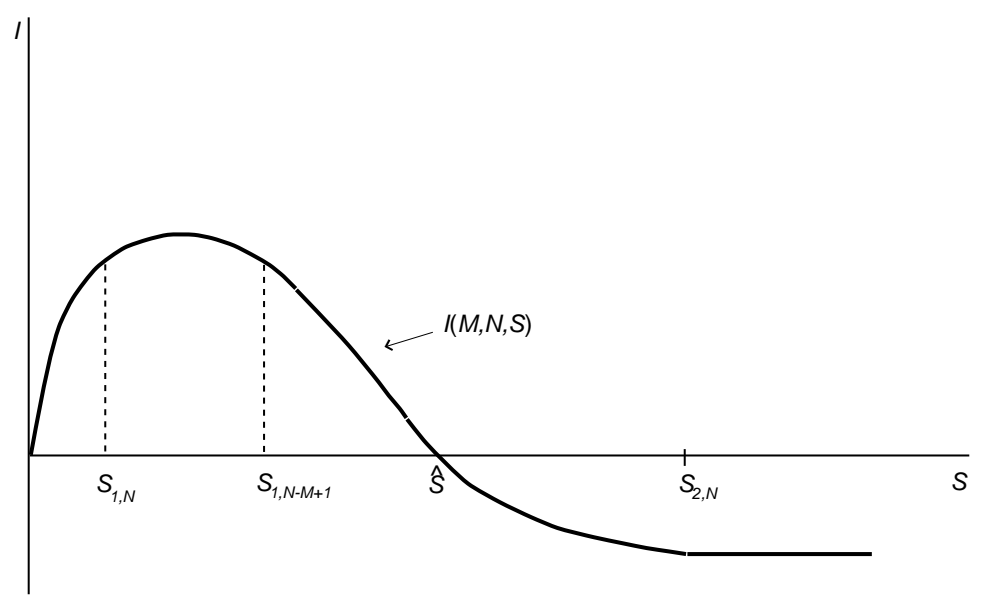

Figure 5: The profitability of the merger as a function of $S$

associated with an additional unit of the resource stock decreases with the stock, and it tends to $+\infty$ as the stock approaches zero. But this marginal rent also depends on the number of firms, which falls when a merger occurs.

From the first-order conditions of the Hamilton-Jacobi-Bellman equation associated with problem (3) to (5), we have that the best response of firm $i$ to the level of production of its $K-1$ rivals is given by

$$
\phi_{i}(S, K)=\operatorname{Max}\left\{0, \frac{a-b \sum_{j \neq i} \phi_{j}(S, K)-\frac{\partial V(S, K)}{\partial S}}{2 b}\right\},
$$

the marginal resource rent being $\frac{\partial V(S, K)}{\partial S}$. In the purely static case that term is zero, since by definition the production decision of all $K$ firms is then independent of $S$, and so therefore is the above reaction function. In such a case, the optimal adjustment of firm $i$ to a change in the overall production of its $K-1$ rivals simply consists in a movement along its reaction function. But in the dynamic resource framework, any attempt to move along the reaction function will result in a shift of that reaction function because of the dynamic link of the stock $S$ to the level of production through the growth function (4). This is obviously highly relevant for the analysis of the equilibrium effects of a merger and its profitability.

When a merger of $M$ firms occurs, the number of firms goes from $K=N$ to $K=N-$ 
$M+1$. In the static Cournot framework, with strategic substitutes, the $N-M$ outsiders to the merger react by increasing their production in response to the reduction in production by the insiders. Whether this results in an increase or decrease of the total equilibrium output, and hence a decrease or increase of the market price, will depend on the relative market share of the merger. As shown by Salant et al. (1983), the joint profit of the insiders will be smaller in the post-merger equilibrium than in pre-merger equilibrium if the proportion of insiders is smaller than some threshold ( $80 \%$ in the linear case). In the dynamic case there is an additional consideration due to the fact that as $K$ changes so does the marginal rent $\frac{\partial V(S, K)}{\partial S}$, with the result that the reaction function (13) will shift. Whether this shift is upward or downward when $K$ decreases will depend on whether the marginal rent decreases or increases with $K$.

To see that both cases can occur, consider the expression for the marginal rent in (10) over the interval $\left[S_{1, K}, S_{2, K}\right]$. Recalling that $W(S, K)=\frac{1}{2} E S^{2}+D S+G$ and differentiating with respect to $K$, we get

$$
\frac{\partial^{2} V(S, K)}{\partial S \partial K}=\frac{\partial^{2} W(S, K)}{\partial S \partial K}=\frac{\partial E}{\partial K} S+\frac{\partial D}{\partial K} .
$$

Therefore

$$
\frac{\partial^{2} V(S, K)}{\partial S \partial K} \gtreqless 0 \quad \text { for } \quad S \gtreqless S_{R} \equiv-\frac{\frac{\partial D}{\partial K}}{\frac{\partial E}{\partial K}}=\frac{a}{\delta b(1+K)} .
$$

Note that $S_{R} \in\left(S_{1, K}, S_{2, K}\right)$. Indeed ${ }^{7}$

$$
S_{R}-S_{1, K}=\frac{a K}{\delta b(1+K)}\left(\frac{2 \delta-r+r K}{(2 \delta-r)(1+K)}\right)>0
$$

and

$$
S_{R}-S_{2, K}=\frac{a K}{\delta b(1+K)}\left(\frac{1-K^{2}}{1+K}\right)<0 \quad \text { for } \quad K \geq 2 .
$$

The fact that $\frac{\partial^{2} W(S, K)}{\partial S \partial K}<0$ for $S \in\left[S_{1, K}, S_{R}\right)$ means that within that range a reduction in the number of firms results in an increase of the marginal valuation of the resource stock

\footnotetext{
${ }^{7}$ As already noted, from (7) and (8), the interval $\left[S_{1, K}, S_{2, K}\right]$ itself increases with $K$.
} 
by each firm. When a merger occurs $K$ decreases from $N$ to $N-M+1$, which therefore results in an increase of the marginal resource rent for $S \in\left[S_{1, K}, S_{R}\right)$ and ultimately in a more 'conservative' reaction function of each firm: for any level of overall production by its rivals, the optimal production of an outsider firm $i$ is smaller after the merger than it was before the merger. Therefore, while a decrease in production by the members of the merger is met by an increase of the production of each of the outsiders in the absence of resource rents (the strategic substitution effect), the presence of the resource rent may diminish such an increase and may even go so far as to also reduce the production of the outsiders. It is this 'moderation' of the reaction of the outsiders to a decrease in production by the insiders, due to the presence of the resource rent, that explains the fact that there is always a range of the stock for which any merger is profitable and that can render profitable a merger which would otherwise have been unprofitable.

\section{Conclusion}

An important characteristic of oligopolistic quantity competition between players whose output is the product of the exploitation of a renewable asset under common property is that there exists a direct physical link between the rate of exploitation (the decision variable) and the remaining common stock of the asset (the state variable). No such link exists in the corresponding static oligopoly, where any given rate of production can be sustained forever, the "state of the system" remaining unaffected, by definition of the static framework. We have shown that this difference is crucial for the analysis of the effects on the equilibrium outcomes of a merger of a subset of the players for the purpose of maximizing their joint profits.

We have modeled the dynamic problem as a closed-loop non-cooperative differential game. The primitives of the problem and the assumptions have been carefully chosen so as to facilitate a direct comparison of the dynamic equilibrium effects of a merger with the well known static equilibrium effects, first elaborated by Salant et al. (1983) in their study of the profitability of exogenous mergers in a static Cournot competition setting. We analyze 
the effect of the merger on the equilibrium production strategies, on the steady-states and the profits of the insiders, with some emphasis put on the latter. It turns out that the presence of the dynamic link between the decision and state variables can drastically alter the conclusions, when compared to the corresponding static game. Whereas in the static framework the outsiders always react to the reduction of output by the insiders by increasing their own output, in the dynamic setting they may react more moderately and may actually, in some instances, also reduce their output. This is because, for some interval of the stock at the time the merger is formed, the merger will have the effect of increasing the value attached by each player to the marginal unit of remaining stock. A consequence is that there is always an interval of initial stock such that any merger is profitable. This is true even of mergers which would not have been profitable in the absence of the stock dynamics.

We have intentionally restricted our attention to exogenously determined mergers, fixed at the outset of the game, in order to facilitate the comparison with the corresponding static exogenous merger literature. However, one may conjecture from our results that if the decision to form a merger was to be made endogenous, the dynamic evolution of the state and of its valuation by the players could, at least in some instances, increase the likelihood of stable equilibrium mergers occurring, as compared to the static case. But endogenous merger formation in this context remains a very challenging issue for further research, for which our results may hopefully provide a valuable building block. 


\section{Appendix}

\section{A Proof of Proposition 3}

Since, from (7), $S_{1, N}<S_{1, N-M+1}$, we know that $\Phi_{N-M+1}^{*}(S)=0<\Phi_{N}^{*}(S)$ for all $S_{1, N}<$ $S \leq S_{1, N-M+1}$. We also know that $\Phi_{N-M+1}^{*}(S)=\Phi_{N}^{*}(S)=0$ for $S \leq S_{1, N}$. Furthermore, for $S>S_{2, N}$ we have

$$
\Phi_{N-M+1}^{*}(S)=\frac{a(N-M+1)}{b(N-M+2)}<\Phi_{N}^{*}(S)=\frac{a N}{b(N+1)} .
$$

To prove the claim it is therefore sufficient to exhibit a level of $S_{1, N-M+1}<S \leq S_{2, N-M+1}$ such that $\Phi_{N-M+1}^{*}(S)>\Phi_{N}^{*}(S)$. In particular, it is sufficient to show that at $S=S_{2, N-M+1}$ we have

$$
\Phi_{N-M+1}^{*}\left(S_{2, N-M+1}\right)=\frac{a(N-M+1)}{b(N-M+2)}>\Phi_{N}^{*}\left(S_{2, N-M+1}\right),
$$

where, from Proposition 1,

$$
\Phi_{N}^{*}\left(S_{2, N-M+1}\right)=N\left(\frac{a-\frac{a\left(1+N^{2}\right)}{2 N^{2} \delta}(2 \delta-r)}{(1+N) b}+\left(\delta-\frac{1}{2} r\right) \frac{(N+1)}{N^{2}} \frac{a\left(1+(N-M+1)^{2}\right)}{\delta b(N-M+2)^{2}}\right) .
$$

After simplification we find that

$$
\Phi_{N-M+1}^{*}\left(S_{2, N-M+1}\right)-\Phi_{N}^{*}\left(S_{2, N-M+1}\right)=\frac{a(M-1) \Delta}{\delta b(N-M+2)^{2}(N+1) N},
$$

where

$$
\Delta \equiv \delta\left[N^{2}-M N-2\right]-r\left[N^{2}-M N+N-1\right] .
$$

The sign of $\Phi_{N-M+1}^{*}\left(S_{2, N-M+1}\right)-\Phi_{N}^{*}\left(S_{2, N-M+1}\right)$ is therefore the same as the sign of $\Delta$.

Note that for all $M<N, \Delta$ is an increasing function of $\delta$. From Assumption $1, \delta>$ $\frac{r}{2}\left(1+N^{2}\right)$ and thus

$$
\Delta>\frac{r}{2}\left(1+N^{2}\right)\left[N^{2}-M N-2\right]-r\left[N^{2}-M N+N-1\right],
$$


which after simplification yields

$$
\left.\Delta>\left(-\frac{1}{2}\right) r N(N+1)[(N-M)(1-N))+2\right] .
$$

We now argue that $((N-M)(1-N)+2) \leq 0$ for all $M<N, N>2$. First note that the expression $(N-M)(1-N)+2$ is strictly increasing in $M$. Therefore, if it is weakly negative for $M=N-1$, it will also be for any $M<N$. For $M=N-1$ the expression becomes

$$
(N-M)(1-N)+2=3-N
$$

which is zero for $N=3$ and strictly negative for $N>3$. Therefore, for $N>2$ we have $\Delta>0$ for all $M<N$ and

$$
\Phi_{N-M+1}^{*}\left(S_{2, N-M+1}\right)-\Phi_{N}^{*}\left(S_{2, N-M+1}\right)>0
$$

It follows that the linear curves in $S, \Phi_{N-M+1}^{*}(S)$ and $\Phi_{N}^{*}(S)$, must intersect once at some $\hat{S}_{1} \in\left(S_{1, N-M+1}, S_{2, N-M+1}\right)$, and once at some $\hat{S}_{2} \in\left(S_{2, N-M+1}, S_{2, N}\right)$.

\section{B Proof of Proposition 4}

The function $I(M, N, S)$ is continuously differentiable in $S$ since the value functions are.

1. That $I(M, N, S)$ is independent of $S$ in Region I follows immediately from the fact that the equilibrium production strategy is the static Cournot strategy both before and after the merger in that region.

2. For $S \in\left[S_{1, N-N+1}, S_{2, N-M+1}\right]$ the first derivative of $I(M, N, S)$ with respect to $S$ is

$$
\begin{aligned}
& \frac{\partial I(M, N, S)}{\partial S}= \\
& \frac{1}{2} \frac{a}{\delta(N-M+1)^{2}}(2 \delta-r)\left((N-M+1)^{2}+1\right)-\frac{1}{2} \frac{M}{N^{2}} \frac{a}{\delta}\left(N^{2}+1\right)(2 \delta-r) \\
+ & 2\left(\frac{1}{2} \frac{b}{(N-M+1)^{2}}(N-M+2)^{2}\left(\frac{1}{2} r-\delta\right)-\frac{1}{2} \frac{M}{N^{2}} b(N+1)^{2}\left(\frac{1}{2} r-\delta\right)\right) S,
\end{aligned}
$$


which is linear in $S$. The second derivative is

$$
\frac{\partial^{2} I}{\partial S^{2}}=\frac{1}{4}(M-1) b(2 \delta-r) \frac{g(M, N)}{(N-M+1)^{2} N^{2}},
$$

where

$g(M, N)=M^{2}-4 M N-M+4 N^{2}+4 N^{3}+N^{4}-6 M N^{2}+2 M^{2} N-2 M N^{3}+M^{2} N^{2}$.

Since

$$
\frac{\partial g}{\partial M}=2\left(1+2 N+N^{2}\right) M-4 N-1-6 N^{2}-2 N^{3}<0
$$

and

$$
g(N, N)=N^{2}-N>0
$$

we have $g(M, N)>0$ for all $M \leq N$. Since $2 \delta-r>0$ by Assumption 1, it follows that $\frac{\partial^{2} I}{\partial S^{2}}>0$. Therefore $\frac{\partial I(M, N, S)}{\partial S}$ is a strictly increasing function of $S$ (and $I(M, N, S)$ strictly convex) for all $S \in\left[S_{1, N-N+1}, S_{2, N-M+1}\right]$.

Evaluated at $S_{2, N-M+1}$, we find that

$$
\frac{\partial I\left(M, N, S_{2, N-M+1}\right)}{\partial S}=-M(M-1) h(M, N) \frac{a(2 \delta-r)}{N^{2} \delta(N-M+2)^{2}},
$$

where

$$
h(M, N)=-N M+N^{2}-1+N .
$$

The function $h(M, N)$ being a strictly decreasing linear function of $M$, we have that $h(M, N)>h(N, N)=N-1>0$ for all $M<N$. This shows that

$$
\frac{\partial I\left(M, N, S_{2, N-M+1}\right)}{\partial S}<0
$$


and therefore

$$
\frac{\partial I(M, N, S)}{\partial S}<0 \quad \text { for all } \quad S \in\left[S_{1, N-N+1}, S_{2, N-M+1}\right]
$$

For $S \in\left[S_{2, N-M+1}, S_{2, N}\right]$ we have

$$
\frac{\partial I(M, N, S)}{\partial S}=\frac{\partial(\Pi(M, N, S)-M \Pi(1, N, S))}{\partial S}=-M \frac{\partial(\Pi(1, N, S))}{\partial S}<0
$$

where the second equality follows from the fact that $\Pi(M, N, S)$ is constant over $\left[S_{2, N-M+1}, S_{2, N}\right]$.

The function $I(M, N, S)$ being continuously differentiable at $S_{2, N-M+1}$ we can therefore state that $\frac{\partial I(M, N, S)}{\partial S}$ is strictly decreasing over $\left[S_{1, N-M+1}, S_{2, N}\right]$.

3. Notice first that since $I(M, N, S)$ is continuously differentiable at $S_{1, N-M+1}$, we will have

$$
\frac{\partial I\left(M, N, S_{1, N-M+1}\right)}{\partial S}<0 .
$$

For all $S$ in this Region III, we have

$$
\begin{aligned}
& I(M, N, S)=\left(\frac{S}{S_{1, N-M+1}}\right)^{\frac{r}{\delta}} \Pi\left(M, N, S_{1, N-M+1}\right)-M \Pi(1, N, S), \\
& \frac{\partial I(M, N, S)}{\partial S}=\frac{r}{\delta}\left(\frac{1}{S_{1, N-M+1}}\right)\left(\frac{S}{S_{1, N-M+1}}\right)^{\frac{r}{\delta}-1}-M \frac{\partial \Pi(1, N, S)}{\partial S}
\end{aligned}
$$

with

$$
\begin{aligned}
\frac{\partial \Pi(1, N, S)}{\partial S}=\frac{1}{2} \delta^{-1} N^{-2}\left(a\left(1+N^{2}\right)-\delta b S(1+N)^{2}\right)(2 \delta-r) \\
\frac{\partial^{2} I(M, N, S)}{\partial S^{2}}=\frac{r}{\delta}\left(\frac{r}{\delta}-1\right)\left(\frac{1}{S_{1, N-M+1}}\right)^{2}\left(\frac{S}{S_{1, N-M+1}}\right)^{\frac{r}{\delta}-2} \Pi\left(M, N, S_{1, N-M+1}\right) \\
-\left(\frac{1}{2} r-\delta\right) \frac{b(N+1)^{2}}{N^{2}}
\end{aligned}
$$


and

$\frac{\partial^{3} I(M, N, S)}{\partial S^{3}}=\frac{r}{\delta}\left(\frac{r}{\delta}-1\right)\left(\frac{r}{\delta}-2\right)\left(\frac{1}{S_{1, N-M+1}}\right)^{3}\left(\frac{S}{S_{1, N-M+1}}\right)^{\frac{r}{\delta}-3} \Pi\left(M, N, S_{1, N-M+1}\right)>0$

It follows that

$$
\frac{\partial^{2} I(M, N, S)}{\partial S^{2}}<\frac{\partial^{2} I\left(M, N, S_{1, N-M+1}\right)}{\partial S^{2}} \text { for all } S \text { in Region III, }
$$

where

$$
\frac{\partial^{2} I\left(M, N, S_{1, N-M+1}\right)}{\partial S^{2}}=-\frac{1}{2} \frac{f(\delta)(2 \delta-r) b}{\left(2 \delta-r\left(1+(M-1-N)^{2}\right)\right) N^{2}}
$$

with

$$
\begin{aligned}
f(\delta) & =2 M r+6 M N r-2 M^{2} r+M^{3} r-8 N^{2} r-8 N^{3} r-2 N^{4} r+15 M N^{2} r \\
& -6 M^{2} N r+8 M N^{3} r+2 M^{3} N r+M N^{4} r-8 M^{2} N^{2} r-2 M^{2} N^{3} r+M^{3} N^{2} r \\
& +\delta\left(8 N^{2}-4 M N-2 M+8 N^{3}+2 N^{4}-10 M N^{2}-4 M N^{3}+2 M^{2} N^{2}\right) .
\end{aligned}
$$

By Assumption 1, the denominator is positive and therefore the sign of $\frac{\partial^{2} I\left(M, N, S_{1, N-M+1}\right)}{\partial S^{2}}$ is the opposite of that of $f(\delta)$. The function $f(\delta)$ is linear in $\delta$ with slope

$$
f^{\prime}(\delta)=8 N^{2}-4 M N-2 M+8 N^{3}+2 N^{4}-10 M N^{2}-4 M N^{3}+2 M^{2} N^{2}>0 .
$$

Since $\delta>\delta_{0}$ by Assumption 1, this means that

$$
f(\delta)>f\left(\delta_{0}\right) \text { for all } \delta>\delta_{0}
$$

where

$$
f\left(\delta_{0}\right)=r(N+1) \beta(M, N)>0,
$$


with

$$
\begin{aligned}
\beta(M, N) & =M+3 M N-2 M^{2}+M^{3}-4 N^{2}+3 N^{4}+N^{5}+6 M N^{2}-4 M^{2} N \\
& -2 M N^{3}+M^{3} N-2 M N^{4}-3 M^{2} N^{2}+M^{2} N^{3}>0 .
\end{aligned}
$$

Therefore

$$
\frac{\partial^{2} I\left(M, N, S_{1, N-M+1}\right)}{\partial S^{2}}<0
$$

It follows that

$$
\frac{\partial^{2} I(M, N, S)}{\partial S^{2}}<\frac{\partial^{2} I\left(M, N, S_{1, N-M+1}\right)}{\partial S^{2}}<0 \quad \text { for all } S \text { in Region III. }
$$

The function $I(M, N, S)$ being strictly concave, we can state that

$$
\frac{\partial I\left(M, N, S_{1, N}\right)}{\partial S}>\frac{\partial I(M, N, S)}{\partial S}>\frac{\partial I\left(M, N, S_{1, N-M+1}\right)}{\partial S}
$$

Furthermore, for $\delta=\delta_{0}$ it is easily verified that $\frac{\partial I\left(M, N, S_{1, N}\right)}{\partial S}>0$. Therefore $I(M, N, S)$ reaches a maximum in Region III.

4. For $S<S_{1, N}$ we have

$$
\begin{aligned}
I(M, N, S) & =\left(\frac{S}{S_{1, N-M+1}}\right)^{\frac{r}{\delta}} \Pi\left(M, N, S_{1, N-M+1}\right)-M\left(\frac{S}{S_{1, N}}\right)^{\frac{r}{\delta}} \Pi\left(1, N, S_{1, N}\right) \\
& =(S)^{\frac{r}{\delta}}\left(\frac{\Pi\left(M, N, S_{1, N-M+1}\right)}{\left(S_{1, N-M+1}\right)^{\frac{r}{\delta}}}-M \frac{\Pi\left(1, N, S_{1, N}\right)}{\left(S_{1, N}\right)^{\frac{r}{\delta}}}\right),
\end{aligned}
$$

from which can conclude that the profitability function $I\left(M, N, S_{1, N}\right)$ does not change sign over $\left(0, S_{1, N}\right)$. The function $I\left(M, N, S_{1, N}\right)$ being continuously differentiable at $S_{1, N}$, we will have

$$
\frac{\partial I\left(M, N, S_{1, N}\right)}{\partial S}>0
$$


and therefore

$$
\frac{\partial I(M, N, S)}{\partial S}>0 \text { for all } S \text { in Region IV. }
$$

\section{Proof of Proposition 5}

When $M=2$ we have

$$
S_{1, N-M+1}=S_{1, N-1}=\frac{\left(2 \delta-r\left(1+(N-1)^{2}\right)\right) a}{(2 \delta-r)(N)^{2} b \delta}
$$

and

$$
I\left(2, N, S_{1, N-M+1}\right)=I\left(2, N, S_{1, N-2+1}\right)=\frac{1}{N^{6}} \frac{a^{2} r}{b \delta^{2}\left(2 \frac{\delta}{r}-1\right)(N+1)^{2}} G\left(\frac{\delta}{r}, N\right)
$$

where the function $G$ is given by

$$
\begin{aligned}
G\left(\frac{\delta}{r}, N\right) & =-2 N^{4}\left(-2 N+N^{2}-1\right)\left(\frac{\delta}{r}\right)^{3} \\
& +\left(N^{8}+3 N^{6}-10 N^{5}-6 N^{4}+8 N^{2}+8 N+2\right)\left(\frac{\delta}{r}\right)^{2} \\
& -4\left(-N+N^{2}-1\right)\left(-2 N+N^{4}-1\right)\left(\frac{\delta}{r}\right)+2\left(-N+N^{2}-1\right)^{2}
\end{aligned}
$$

The sign of $I\left(2, N, S_{1, N-2+1}\right)$ is the same as the sign of $G\left(\frac{\delta}{r}, N\right)$ since $\left(2 \frac{\delta}{r}-1\right)>0$ from Assumption 1. We now study the sign of $G$.

Let $\rho=\delta / r$. The function $G$ is a polynomial of degree 3 in $\rho$. The coefficient of $\rho^{3}$ being strictly negative for all $N \geq 3, G$ is an inverted N-shaped function of $\rho$. Therefore $G<0$ when $\rho \equiv \delta / r$ is large enough. We now show that

(i) $\frac{\partial^{2} G(\rho, N)}{\partial \rho^{2}}<0$ for all $\rho$ that satisfies Assumption 1 (i.e. $\rho \equiv \delta / r>\left(1+N^{2}\right) / 2$ ). For this we only need to show that

$$
\frac{\partial^{2} G\left(\frac{1}{2}\left(1+N^{2}\right), N\right)}{\partial \rho^{2}}<0
$$


(ii) $G\left(\frac{1}{2}\left(1+N^{2}\right), N\right)>0$.

Having established (i) and (ii), combined with the fact that $G<0$ when $\rho$ is large enough, will allow us to state that there exists a unique $\hat{\rho}>\left(1+N^{2}\right) / 2$, and hence, for any given $r$, a unique $\hat{\delta}=r \hat{\rho}>\frac{r}{2}\left(1+N^{2}\right)$ such that

$$
G\left(\frac{\delta}{r}, N\right)>0 \text { for all } \delta \in\left[\frac{r}{2}\left(1+N^{2}\right), \hat{\delta}\right) \text { and } G\left(\frac{\delta}{r}, N\right)<0 \text { for all } \delta>\hat{\delta}
$$

and thus

$$
I\left(2, N, S_{1, N-2+1}\right)>0 \text { for all } \delta \in\left[\frac{r}{2}\left(1+N^{2}\right), \hat{\delta}\right) \text { and } I\left(2, N, S_{1, N-2+1}\right)<0 \text { for all } \delta>\hat{\delta} \text {. }
$$

Consider (i). Differentiating $G$ twice with respect to $\rho$ we find that

$\frac{\partial^{2} G(\rho, N)}{\partial \rho^{2}}=\left(24 N^{5}-12 N^{6}+12 N^{4}\right) \rho+\left(2 N^{8}+6 N^{6}-20 N^{5}-12 N^{4}+16 N^{2}+16 N+4\right)$,

which, when evaluated at $\rho=\left(1+N^{2}\right) / 2$, can be written

$$
\frac{\partial^{2} G\left(\frac{1}{2}\left(1+N^{2}\right), N\right)}{\partial \rho^{2}}=2 N^{6}\left(3+6 N-2 N^{2}\right)+l(N),
$$

where $l(N) \equiv-8 N^{5}-6 N^{4}+16 N^{2}+16 N+4$.

The first term is strictly negative for all $N \geq 3$. We now argue that $l(N)$ is strictly negative as well for all $N \geq 3$. Indeed

$$
l^{\prime}(N)=-40 N^{4}-24 N^{3}+32 N+16
$$

and

$$
l^{\prime \prime}(N)=-160 N^{3}-72 N^{2}+32<0 .
$$

Since $l^{\prime}(3)=-11632<0$, it follows that $l^{\prime}(N)<l^{\prime}(3)<0$ and $l$ is strictly decreasing in 
$N$, with $l(3)=-2234$. Therefore $l(N)<0$ for all $N \geq 3$. This shows that

$$
\frac{\partial^{2} G\left(\frac{1}{2}\left(1+N^{2}\right), N\right)}{\partial \rho^{2}}<0
$$

and completes the proof of (i).

As for (ii), evaluating $G$ at $\rho=\frac{1}{2}\left(1+N^{2}\right)$, we obtain

$$
G\left(\frac{1}{2}\left(1+N^{2}\right), N\right)=-\frac{1}{4}(N+1)^{2} Z(N)
$$

where

$$
Z(N) \equiv N^{7}\left(4+N-2 N^{2}\right)+N^{4}\left(11+6 N-2 N^{2}\right)+2(1-N)\left(4 N^{2}+N-1\right) .
$$

All three terms in $Z(N)$ being strictly negative for $N \geq 3$, so is $Z(N)$. Therefore

$$
G\left(\frac{1}{2}\left(1+N^{2}\right), N\right)>0
$$

which completes the proof (ii) and therefore that of Proposition 5 . 


\section{References}

Benchekroun, Hassan (2003) 'Unilateral production restrictions in a dynamic duopoly.' Journal of Economic Theory 111, 214-239

_ (2008) 'Comparative dynamics in a productive asset oligopoly.' Journal of Economic Theory $138,237-261$

Benhabib, J., and R. Radner (1992) 'The joint exploitation of a productive asset: a game theoretic approach.' Economic Theory 2, 155-190

Clark, Colin W. (1990) Mathematical bioeconomics: The optimal management of renewable resources, second ed. (New York: Wiley)

Clemhout, S., and H. Y. Wan (1991) 'Environmental problem as a common property resource game.' In Dynamic Games in Economic Analyses, ed. R.P. Hämäläinen and H.K. Ehtamo (Berlin: Springer-Verlag)

Colombo, Luca, and Paolo Labrecciosa (2013) 'Oligopoly exploitation of a private property productive asset.' Journal of Economic Dynamics and Control 37, 838-853

Dockner, E., and G. Sorger (1996) 'Existence and properties of equilibria for a dynamic game on productive assets.' Journal of Economic Theory 71, 209-227

Dockner, E., S. Jorgensen, N. V. Long, and G. Sorger (2000) Differential Games in Economics and Management Science (Cambridge: Cambridge University Press)

Dutta, P.K., and R.K. Sundaram (1993a) 'The tragedy of the commons.' Economic Theory $3,413-426$

_ (1993b) 'How different can strategic models be?' Journal of Economic Theory 60, 42-61

Eswaran, M., and T. Lewis (1984) 'Appropriability and the extraction of a common property resource.' Economica 51, 393-400

Fujiwara, Kenji (2011) 'Losses from competition in a dynamic game model of a renewable resource oligopoly.' Resource and Energy Economics 33, 1-11

Gaudet, Gérard, and Stephen W. Salant (1991) 'Increasing the profits of a subset of firms in oligopoly models with strategic substitutes.' American Economic Review 81, 658-665

Karp, Larry (1992a) 'Efficiency inducing tax for a common property oligopoly.' Economic Journal 102, 321-332

_ (1992b) 'Social welfare in a common property oligopoly.' International Economic Review $33,353-372$

Levhari, D., and L. J. Mirman (1980) 'The great fish war: An example using a dynamic Cournot-Nash solution.' Bell Journal of Economics 11, 322-334 
Mason, C., and S. Polasky (1997) 'The optimal number of firms in the commons: A dynamic approach.' Canadian Journal of Economics 30, 1143-1160

Plourde, C., and D. Yeung (1989) 'Harvesting of a transboundary replenishable fish stock: A noncooperative solution.' Marine Resource Economics 6, 57-70

Salant, S. W., S. Switzer, and R.J. Reynolds (1983) 'Losses from horizontal merger: The effects of an exogenous change in industry structure on Cournot-Nash equilibrium.' Quarterly Journal of Economics 98, 185-199 


\section{Récents cahiers de recherche du CIREQ Recent Working Papers of CIREQ}

Si vous désirez obtenir des exemplaires des cahiers, vous pouvez les télécharger à partir de notre site Web http://www.cireqmontreal.com/cahiers-de-recherche

If you wish to obtain copies of the working papers, you can download them directly from our website, http://www.cireqmontreal.com/cahiers-de-recherche

17-2012 Ruge-Murcia, F., "Skewness Risk and Bond Prices", mai 2012, 41 pages

18-2012 Amarante, M., M. Ghossoub, E. Phelps, "Contracting for Innovation under Knightian Uncertainty", septembre 2012, 37 pages

19-2012 Bossert, W., C. D'Ambrosio, "Proximity-Sensitive Individual Deprivation Measures", décembre 2012, 15 pages

01-2013 Bossert, W., Y. Sprumont, "Every Choice Function is Backwards-Induction Rationalizable", janvier 2013, 15 pages

02-2013 Amarante, M., "Conditional Expected Utility", février 2013, 19 pages

03-2013 Benchekroun, H., F. Taherkhani, "Adaptation and the Allocation of Pollution Reduction Costs", mai 2013, 33 pages

04-2013 Bossert, W., H. Peters, "Single-Basined Choice", juin 2013, 15 pages

05-2013 Okasha, S., J.A. Weymark, W. Bossert, "Inclusive Fitness Maximization : An Axiomatic Approach", mai 2013, 17 pages

06-2013 Ehlers, L., B. Klaus, "House Allocation via Deferred-Acceptance", juillet 2013, 13 pages

07-2013 McCausland, W.J., A.A.J. Marley, "Bayesian Inference and Model Comparison for Random Choice Structures", juillet 2013, 26 pages

08-2013 Cardia, E., P. Gomme, "The Household Revolution : Childcare, Housework, and Female Labor Force Participation", juillet 2013, 44 pages

09-2013 Dutta, R., S. Horan, "Inferring Rationales from Choice : Identification for Rational Shortlist Methods", mars 2013, 51 pages

10-2013 Dutta, R., R. Ishii, "Coordinating by Not Committing : Efficiency as the Unique Outcome", août 2013, 38 pages

11-2013 Amarante, M., "A Representation of Risk Measures", octobre 2013, 8 pages

12-2013 Amarante, M., "A Characterization of Exact Non-atomic Market Games", octobre 2013, 8 pages

13-2013 Dufour, J.-M., L. Khalaf, M. Voia, "Finite-Sample Resampling-Based Combined Hypothesis Tests, with Applications to Serial Correlation and Predictability", octobre 2013, 23 pages

14-2013 Zhang, H.J., J.-M. Dufour, J.W. Galbraith, "Exchange Rates and Commodity Prices : Measuring Causality at Multiple Horizons", septembre 2013, 41 pages

15-2013 Gaudet, G., P. Lasserre, "The Taxation of Nonrenewable Natural Resources", octobre 2013, 41 pages 